\title{
Epithermal Neutron Beam Interference with Cardiac Pacemakers
}

\author{
Koivunoro, Hanna
}

2010

Koivunoro , H , Seren , T , Hyvönen , H , Kotiluoto , P , livonen, P , Auterinen , I ,

Kankaanranta , L , Pakarinen , S , Tenhunen , M \& Savolainen, S 2010 , Epithermal

Neutron Beam Interference with Cardiac Pacemakers . in New Challenges in Neutron

Capture Therapy 2010 : Proceedings of 14th International Congress on Neutron Capture

Therapy . pp. 269-271 , International Congress on Neutron Capture Therapy , Buenos Aires

, Argentina , 25/10/2010 .

http://hdl.handle.net/10138/18447

submittedVersion

Downloaded from Helda, University of Helsinki institutional repository.

This is an electronic reprint of the original article.

This reprint may differ from the original in pagination and typographic detail.

Please cite the original version. 


\title{
Epithermal Neutron Beam Interference with Cardiac Pacemakers
}

\author{
H. Koivunoro ${ }^{1,2,3}$, T. Serén ${ }^{4}$, H. Hyvönen ${ }^{3}$, P. Kotiluoto ${ }^{4}$, P. Iivonen 5 , I. Auterinen ${ }^{4}$, T. Seppälä ${ }^{2}$, L. \\ Kankaanranta $^{2}$, S. Pakarinen ${ }^{6}$, M. Tenhunen ${ }^{2}$, S. Savolainen ${ }^{7}$ \\ ${ }^{1}$ Department of Physics, POB 64, FI-00014 University of Helsinki, ${ }^{2}$ Department of Oncology, Helsinki \\ University Central Hospital, ${ }^{3}$ Boneca Corporation, ${ }^{4}$ VTT Technical Research Centre of Finland, ${ }^{5}$ St. Jude \\ Medical Finland, ${ }^{6}$ Department of Cardiology, Helsinki University Central Hospital, ${ }^{7}$ HUS Helsinki Medical \\ Imaging Center, Helsinki University Central Hospital
}

\begin{abstract}
A patient with implanted cardiac pacemaker may be a candidate for BNCT. In this paper, a phantom study was performed to evaluate the effect of an epithermal neutron beam irradiation on the cardiac pacemaker function. The neutron and photon doses at pacemaker typical location were calculated with the SERA treatment planning system for a typical neck area tumor patient. Approximately similar irradiation conditions were reproduced in a large water phantom computed using the MCNP5 program. Two cardiac pacemaker models were irradiated with the FiR 1 epithermal neutron beam. The neutron fluences were determined at the pacemaker locations using diluted $\mathrm{Mn}$ and $\mathrm{Au}$ activation foils. The photon dose was determined using a $\mathrm{Mg}(\mathrm{Ar})$ ionization chamber. Severe malfunction occurred in case of both pacemakers. Both pacemakers got activated, the main detected radionuclides being ${ }^{198} \mathrm{Au},{ }^{128} \mathrm{I},{ }^{194} \mathrm{Ir},{ }^{56} \mathrm{Mn},{ }^{38} \mathrm{Cl}$ and ${ }^{187} \mathrm{~W}$ with half-lives from 25 minutes to 2.7 days. These results suggest that substantially lower dose from epithermal neutron irradiation causes permanent damage or severe malfunction in the pacemaker than has been observed in the fast neutron or photon beam irradiations at the same photon dose rate level. In addition, pacemaker components get activated in the epithermal neutron beam irradiation causing additional radiation dose to the patient and risk of unexpected memory changes in the pacemaker's microprocessor that may cause malfunction to the device also after BNCT irradiation. Thus BNCT should be administrated only after removal of the pacemaker from the vicinity of the tumor.
\end{abstract}

Keywords: Neutron activation, pacemaker, MCNP, SERA

\section{Introduction}

A patient with implanted cardiac pacemaker may be a candidate for BNCT. Radiation may cause permanent damage or temporary malfunctions on semiconductor materials found in pacemakers. For the safe pacemaker functioning during photon radiotherapy, it has been suggested, that the pacemaker should not be placed in the direct therapy beam and the cumulative dose to pacemaker is limited to 2 Gy (Marbach et al. 1994). Wide photon dose rage (0.5-40 Gy) has reported to affect pacemaker function (Tondato et al. 2009, Oshiro et al. 2008). Permanent damage can occur to a pacemaker after exposure to $10 \mathrm{~Gy}$ in a photon beam irradiation (Last 1998, Marbach et al 1994). Maximum tolerable cumulative radiation dose for safe operation of pacemakers depends highly on pacemaker type and model as well as on the dose rate (Mouton et al. 2002). Modern pacemakers with complimentary metal oxide semiconductor (CMOS) circuits are more radiosensitive than older pacemakers with nonprogrammable bipolar semiconductors (Solan et al. 2004). For the modern pacemakers in a high- energy photon beam irradiation, a maximum dose rate of $12 \mathrm{~Gy} / \mathrm{h}$ rejecting direct irradiation of the pacemaker is recommended for the safe operation of pacemakers, while no malfunction has been observed with the dose rates lower than $3 \mathrm{~Gy} / \mathrm{h}$ (Mouton et al. 2002). Usual recommendation of the pacemaker manufacturers is that the total cumulative dose should never exceed 5 Gy. Protons and neutrons with densely ionizing tracks are more likely to cause damage than photons. Minor pacemaker changes have been detected during proton beam therapy caused by scattered neutrons (Oshiro et al. 2008). Catastrophic pacemaker malfunction has been reported during fast neutron therapy at a dose of only 0.9 Gy (Raitt et al. 1994). The pacemaker was not permanently damaged due to 0.9 Gy fast neutron dose, but its programming code was significantly corrupted. Interference of a neutron beam used for BNCT with a pacemaker has not yet been reported in the literature. A phantom study was performed to evaluate impact of an epithermal neutron beam irradiation on the cardiac pacemaker function. 


\section{Materials and Methods}

Neutron fluence and photon dose at typical pacemaker location was calculated with the SERA treatment planning system for a neck area tumor patient. At the pacemaker located at $10 \mathrm{~cm}$ distance from the beam aperture edge at about $0.5 \mathrm{~cm}$ depth under skin maximum fluence rate of thermal $(\mathrm{E}<0.414 \mathrm{eV})$ neutrons was $1.8 \times 10^{8}$ neutrons $/ \mathrm{cm}^{2} / \mathrm{s}$, epithermal $(0.414$ $\mathrm{eV}<\mathrm{E}<9.12 \mathrm{keV}$ ) neutrons $1.8 \times 10^{8}$ neutrons $/ \mathrm{cm}^{2} / \mathrm{s}$ and fast neutrons $(\mathrm{E}>9.12 \mathrm{keV}) 8.2 \times 10^{6}$ neutrons/ $\mathrm{cm}^{2} / \mathrm{s}$. The maximum fast neutron dose rate calculated in soft tissue $(10.1 \mathrm{w}-\%$ of hydrogen and $2.6 \mathrm{w}-\%$ of nitrogen) was $0.1 \mathrm{~Gy} / \mathrm{h}$ and maximum thermal neutron dose (due to nitrogen capture) $0.3 \mathrm{~Gy} / \mathrm{h}$. Maximum photon dose rate at the pacemaker location was 1.3 $\mathrm{Gy} / \mathrm{h}$. Approximately similar irradiation conditions were reproduced in a water phantom. A large (51 $\mathrm{cm} \times 51 \mathrm{~cm} \times 47 \mathrm{~cm}$ ) cubical water phantom with 1 $\mathrm{cm}$ thick PMMA walls and $0.5 \mathrm{~cm}$ thick beam side window $(\varnothing 30 \mathrm{~cm})$ was applied.

Two cardiac pacemaker models (Verity ADx XL DR 5356 and Zephyr DR 5820) of St Jude Medical were tested in the FiR 1 epithermal neutron beam. Both models are of modern type using CMOS circuitry. The pacemakers were attached on the 0.5 $\mathrm{cm}$ thick phantom inner wall at $9 \mathrm{~cm}$ (Zephyr) and $13 \mathrm{~cm}$ (Verity) off the $14 \mathrm{~cm}$ diameter beam central axis (Figure 1). The phantom was placed at the 10 $\mathrm{cm}$ distance from the beam aperture plane.

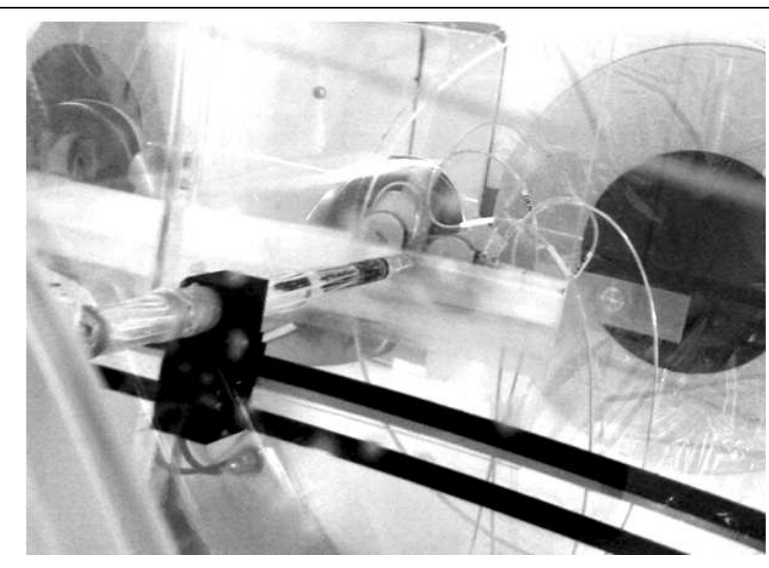

Figure 1. Exradin $\mathrm{Mg}(\mathrm{Ar})$ ionization chamber, activation foils and the pacemakers inside the water phantom placed at $10 \mathrm{~cm}$ distance from the $14 \mathrm{~cm}$ circular FiR 1 beam aperture.
The predicted neutron fluences as well as the total neutron and photon doses in water calculated using MCNP5 at the pacemaker locations are shown in table I. Tally F4 was used to determine the fluences and tally F6 the doses. Pacemaker structures were not modeled, since exact elemental composition and structures inside the pacemakers are company confidential information and thus not available from the manufacturer. Thus pacemakers were modeled as $0.5 \mathrm{~cm}$ thick cylindrical water discs with $1.5 \mathrm{~cm}$ radius. In order to verify the MCNP5 calculations, the neutron fluence was determined at the pacemaker location using diluted $\mathrm{MnAl}$ and $\mathrm{AuAl}$ activation foils with $1 \mathrm{w}-\%$ of manganese and gold. The reaction rates were calculated with MCNP5 using $0.1 \mathrm{~cm}$ thick cylindrical tally volumes of $0.5 \mathrm{~cm}$ radius and the $\mathrm{F} 4$ tally with the tally multiplier card scoring the total number of $(\mathrm{n}, \gamma)$ reactions in manganese and gold.

The photon dose was measured using a $\mathrm{Mg}(\mathrm{Ar})$ ionization chamber of Exradin. The ionization chamber was placed behind and between the pacemakers touching them, at $11 \mathrm{~cm}$ off the beam central axis as shown in figure 1. At that location, the chamber measures dose at about $2 \mathrm{~cm}$ behind the pacemakers. The pacemakers were irradiated for an hour, which is about a typical duration of the two-field neck tumor BNCT treatment at FiR 1. The pacemakers were interrogated before and after irradiation, when the pulse voltages and intervals generated by the pacemakers were measured. Also, pacemaker neutron activation itself was measured.

\section{Results and Discussion}

Severe malfunction was detected in case of both pacemakers after the irradiation. Verity went into 'Back-Up mode VVI' due to multiple unexpected memory changes in microprocessor, meaning that the backup program had turned safe pacing rate on. Zephyr lost it's ID bit and cleared the registry due to many severe bit flips. It was impossible to interrogate the device after the irradiation. The both pacemakers got activated due to several nuclides listed in table II. Most of these nuclides are also $\beta$ active. The measured dose rate on the pacemaker surface immediately after the irradiation was 400

Table I. Total thermal, epithermal and fast neutron fluences $\left(\Phi_{\text {thermal }}, \Phi_{\text {epithermal }}\right.$ and $\left.\Phi_{\text {fast }}\right)$ and total absorbed neutron $\left(D_{\text {neutron }}\right)$ and photon doses $\left(\mathrm{D}_{\gamma}\right)$ calculated with the MCNP5 at the Zephyr and Verity pacemaker locations in the water phantom for one hour irradiation.

\begin{tabular}{lcccccc}
\hline & $\begin{array}{c}\text { Distance } \\
\text { from beam } \\
\text { axis } \\
\mathrm{cm}\end{array}$ & $\mathrm{D} g$ & $\mathrm{D}_{\text {neutron }}$ & $\begin{array}{c}\Phi_{\text {thermal }} \\
\times 10^{12} \\
\text { neutrons } / \mathrm{cm}^{2}\end{array}$ & $\begin{array}{c}\Phi_{\text {epithermal }} \\
\times 10^{12} \\
\text { neutrons } / \mathrm{cm}^{2}\end{array}$ & $\begin{array}{c}\Phi_{\text {fast }} \\
\times 10^{12} \\
\text { neutrons } / \mathrm{cm}^{2}\end{array}$ \\
\hline Zephyr & 9 & $2.0 \pm 0.2 \%$ & $0.2 \pm 0.8 \%$ & $1.6 \pm 0.1 \%$ & $1.1 \pm 0.1 \%$ & $0.02 \pm 0.6 \%$ \\
Verity & 13 & $1.2 \pm 0.3 \%$ & $0.1 \pm 1.3 \%$ & $0.8 \pm 0.2 \%$ & $0.5 \pm 0.2 \%$ & $0.009 \pm 1.0 \%$ \\
\hline
\end{tabular}


$\mu \mathrm{Sv} / \mathrm{h}$ for the Zephyr and $150 \mu \mathrm{Sv} / \mathrm{h}$ for the Verity. Calculated ${ }^{55} \mathrm{Mn}(\mathrm{n}, \gamma)$ and ${ }^{197} \mathrm{Au}(\mathrm{n}, \gamma)$ reaction rates agreed with the measurements within $13 \%$ and $9 \%$ respectively. The measured photon dose was 2.6 Gy and the calculated using MCNP5 1.9 Gy at the measurement location. The calculated photon doses at the pacemaker locations were 2.0 Gy and $1.2 \mathrm{~Gy}$. If the actual photon dose would had been $33 \%$ greater, as may be suggested based on the measurement, the actual photon doses at the pacemaker sites would had been 2.7 Gy and $1.6 \mathrm{~Gy}$, with corresponding dose rates of 3.0 and $1.8 \mathrm{~Gy} / \mathrm{h}$. Permanent pacemaker malfunctions has been reported at a dose below $2 \mathrm{~Gy}$ in a photon beam only if the dose is delivered with a dose rate above $30 \mathrm{~Gy} / \mathrm{h}$ (Mouton et al. 2002). In the same study, none of the 96 irradiated pacemakers failed at a dose rate lower than $12 \mathrm{~Gy} / \mathrm{h}$. At $18 \mathrm{MeV}$ photon beam energy, neutrons may play partial role in the radiation damage. At lower (6 MV-10 MV) photon beam energies, permanent pacemaker failure has not been detected at cumulative doses below 10 Gy (Last 1998).

Absorbed neutron dose in the pacemaker is material dependent and thus, exact neutron dose estimation is difficult. In this study, we have reported the absorbed dose calculated in water at the pacemaker location. The calculated epithermal and thermal neutron fluence rate at the pacemaker locations was almost 100 times that of fast neutron fluence. The neutron fluence spectra at the pacemaker locations are shown in figure 2 .

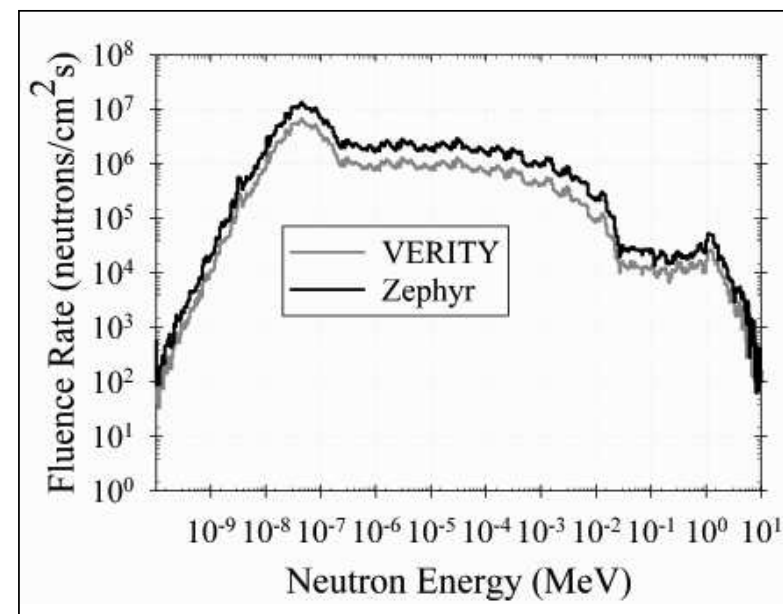

Figure 2. Neutron fluence rate calculated with MCNP5 at the Verity and Zephyr pacemaker locations in the phantom.

The calculated total neutron doses $(0.2$ Gy and 0.1 Gy) to the pacemakers are substantially lower than the fast neutron dose $(0.9 \mathrm{~Gy})$ reported to cause pacemaker malfunction, not permanent damage. Also, determined cumulative photon dose at the Zephyr pacemaker site is substantially lower (2.7 Gy) than the photon doses reported to cause permanent failure (dose limit $10 \mathrm{~Gy}$ ) at the similar dose rate level. We suggest that the observed pacemaker malfunction is
Table II. Major neutron activated radionuclides detected using a HPGE gamma spectrometer after pacemaker irradiation, half-lives $\left(\mathrm{T}_{1 / 2}\right)$ and energies of the principal gammas $(\mathrm{E} \gamma)$.

\begin{tabular}{lll}
\hline Nuclide & $\mathrm{T}_{1 / 2}$ & $\mathrm{E}_{\mathrm{g}}(\mathrm{keV})$ \\
\hline${ }^{128} \mathrm{I}$ & $25.0 \mathrm{~min}$ & 442.9 \\
${ }^{198} \mathrm{Au}$ & $2.695 \mathrm{~d}$ & 411.8 \\
${ }^{187} \mathrm{~W}$ & $23.72 \mathrm{~h}$ & 685.8 \\
${ }^{56} \mathrm{Mn}$ & $2.58 \mathrm{~h}$ & 846.8 \\
${ }^{194} \mathrm{Ir}$ & $19.28 \mathrm{~h}$ & 328.5 \\
${ }^{60} \mathrm{Co}$ & $5.3 \mathrm{y}$ & $1173.2,1332.5$ \\
${ }^{51} \mathrm{Cr}$ & $27.7 \mathrm{~d}$ & 320.1 \\
${ }^{192} \mathrm{Ir}$ & $73.8 \mathrm{~d}$ & 316.5 \\
${ }^{182} \mathrm{Ta}$ & $114.7 \mathrm{~d}$ & $67.8,1121.3$ \\
${ }^{201} \mathrm{Tl}$ & $3.0 \mathrm{~d}$ & 70.8 \\
${ }^{187} \mathrm{~W}$ & $24 \mathrm{~h}$ & 685.8 \\
${ }^{38} \mathrm{Cl}$ & $37.2 \mathrm{~min}$ & 2167.5 \\
\hline
\end{tabular}

mainly due to neutron activation of the pacemaker structures, since the $\beta$-active radionuclides may cause changes in semiconductors inside the device.

\section{Conclusions}

These results suggest that already low neutron dose from epithermal neutron irradiation causes pacemaker malfunction, and thus BNCT should be administrated only after removal and replacement of the pacemaker from the vicinity of the tumor. In addition, pacemaker components get activated in the BNCT beam causing additional radiation dose to patient and risk of unexpected memory changes in the pacemaker's microprocessor that may cause malfunction to the device also after BNCT irradiation.

\section{References}

Last A., 1998. Radiotherapy in patients with cardiac pacemakers. Br J Radiol. 71, 4-10.

Marbach J. R., et al. 1994. Management of radiation oncology patients with implanted cardiac pacemakers: Report of AAPM Task Group No 34. Med. Phys. 21, 85-90.

Mouton J. et al., 2002. Influence of high-energy photon beam irradiation on pacemaker operation. Phys Med Biol. 47, 2879-93.

Oshiro Y, et al., 2008. Proton beam therapy interference with implanted cardiac pacemakers. Int J Radiat Oncol. Biol. Phys. 72, 723-7.

Raitt M. H., et al., 1994. Runaway pacemaker during high-energy neutron radiation therapy. Chest. 106, 955-7.

Solan A. N., et al., 2004. Treatment of patients with cardiac pacemakers and implantable cardioverterdefibrillators during radio-therapy. Int J Radiat Oncol Biol Phys. 59, 897-904.

Tondato F., et al., 2009. Radiotherapy-induced pacemaker and implantable cardioverter defibrillator malfunction. Expert Rev. Med. Devices. 6, 243-9. 